\title{
К вопросу об освобождении от Угомовной ответственности по примечанию к статье 205 Угомовного кодекса Российской Федерации
}

А. И. БыКОВ - научный сотрудник НИЦ-1 Научно-исследовательского института ФСИН России

Ре ферат

В статье рассматривается проблема освобождения от уголовной ответственности по специальной норме ст. 205 УК РФ. Во введении обращается внимание на особую опасность данного вида преступления, так как оно может нанести вред различным объектам уголовно-правовой охраны, а также имеет не локальный, а международный характер. Автор приводит статистические данные о количестве преступлений террористической направленности. В целях предупреждения рассматриваемого вида преступления законодателем была разработана специальная норма, в которой заключается определенное условие, в случае выполнения которого лицо может быть освобождено от уголовной ответственности. Однако при реализации данной нормы возникают некоторые проблемы. Во-первых, встает вопрос о понимании условия, содержащегося в рассматриваемой норме, и его относимости к специальной норме освобождения от уголовной ответственности или добровольному отказу от преступления. В результате анализа автор предлагает свой вариант решения данной проблемы.

Во-вторых, в статье рассматривается вопрос о возможном условии, которое может возникнуть и быть заявлено при предупреждении террористического акта одним из участников, кем было подготовлено общественно опасное деяние в целях предотвращения преступления. Исследователь приводит примеры, иллюстрируя разные ситуации применительно к рассматриваемой проблеме, и дает классификацию требований, способствующих предупреждению террористического акта.

Ключевы е слова: примечание; специальная норма; террористический акт; освобождение от уголовной ответственности; добровольный отказ; классификация.

12.00.08 - Уголовное право и криминология; уголовно-исполнительное право 


\title{
On the issue of exemption from criminal liability under the note to Art. 205 of the Criminal Code of the Russian Federation
}

\begin{abstract}
A. I. BYKOV - Researcher of the Research Center-1 of the Research Institute of the Federal Penal Service of Russia

Abstract

The article discusses the issue of exemption from criminal liability under the special note of Art. 205 of the Criminal Code. The introduction draws attention to the particular danger of this type of crime as it can harm various objects of criminal law protection and also has not a local, but an international character. The author provides statistics on the number of terrorist crimes. In order to prevent the type of crime under consideration the legislator has developed a special rule that stipulates a certain condition, in case of fulfillment of which a person can be exempted from criminal liability. However when implementing this rule, some problems arise. Firstly, the question arises of understanding the conditions contained in the norm under consideration and its relevance to the special norm of exemption from criminal liability or to the voluntary refusal of a crime. As a result of the analysis the author proposes his own solution to this issue.

Secondly, the article considers the question of a possible condition that may arise and be declared when a terrorist act was prevented by one of the participants who prepared a socially dangerous act in order to prevent a crime. The researcher gives examples, illustrating different situations in relation to the problem under consideration and gives a classification of requirements that contribute to the prevention of a terrorist act.

Key words: note; special rule; terrorist act; exemption from criminal liability; voluntary refusal; classification.
\end{abstract}

12.00.08 - Criminal law and criminology; penal law

Терроризм проявляется в различных формах общественно опасных деяний, характеризующихся особой жестокостью и безнравственностью. Проблема террора охватывает не только страну, но и мир в целом, что усложняет поиск методов противодействия данному явлению.

Начиная с конца XX в. угроза терроризма неуклонно возрастает, террористические акты становятся более масштабными и жестокими. Со временем тактика и способы исполнения актов террористической направленности становятся системными, автоматизированными и более продуманными, что дает возможность виновным избежать уголовной ответственности.

По данным ГИАЦ МВД России, в 2015 г. было совершено 1538 преступлений, связанных с террористическими актами, в 2016 г. - 2227, в 2017 г. - 1871, в 2018 г. - 1679, в январе-марте 2019 г. - 482. Следует отметить, что общее число преступлений террористического характера имеет тенденцию к уменьшению. Вместе с тем необходимо помнить, что статистические данные не отражают реальную ситуацию полностью. Кроме того, данные по предупреждению и недопущению терроризма, а также преступления, выявленные и сопряженные с террористической деятельностью, могут не регистрироваться либо иметь другую квалификацию.
Таким образом, терроризм остается серьезной проблемой как для правоохранительных органов, так и для государства в целом.

Акты проявления террористической деятельности имеют повышенную опасность и направлены к различным объектам уголовно-правовой охраны: общественной безопасности, общественному порядку, жизни и здоровью людей и пр. Угроза совершения общественно опасного деяния закреплена в объективной стороне преступления, содержащегося в ст. 205 УК РФ «Террористический акт».

Цель совершения общественно опасного деяния указывает на объект преступления. Цель совершения террористического акта означает, что основным непосредственным объектом его посягательства является безопасность государства [11, с. 110]. Данный факт по своему смыслу имеет место быть, так как именно через действия, содержащиеся в рассматриваемом составе, происходит акт терроризма, целью которого является нарушение безопасности государства и общественного порядка. Дополнительным объектом в данном случае являются жизнь и здоровье людей, отношения собственности, отлаженное функционирование предприятий, учреждений и органов власти.

Исходя из специфики отдельных составов преступлений, предусмотренных Осо- 
бенной частью УК РФ, помимо карательных действий в отношении некоторых лиц, совершивших общественно опасное деяние, законодателем были установлены примечания к ряду статей. Данные нормы входят в механизм уголовно-правовой защиты и направлены на его оптимизацию, одновременно способствуя более полной реализации принципа экономии репрессии [1, с. 11]. Таким образом, рассматриваемая статья содержит примечание, которое заключает в себе специальное условие освобождения от уголовной ответственности, если лицо своевременно предупредило органы власти или иным способом способствовало предотвращению осуществления террористического акта и если в действиях этого лица не содержится иного состава преступления.

Исходя из содержания ч. 1 ст. 205 УК РФ, террористический акт представляет собой совершение взрыва, поджога или иных действий, устрашающих население и создающих опасность гибели человека, причинения значительного имущественного ущерба либо наступления иных тяжких последствий, в целях дестабилизации деятельности органов власти или международных организаций либо воздействия на принятие ими решений, а также угрозу совершения указанных действий в целях воздействия на принятие решений органами власти или международными организациями. Данное понятие содержит два основных деяния, которые относятся к террористическому акту: 1) взрыв, поджог и иные действия, устрашающие население и создающие опасность гибели человека, причинения значительного имущественного ущерба либо наступления иных тяжких последствий и 2) угроза указанных действий. Каждое из этих проявлений террористического акта имеет свой смысл и обусловливает специфику применения специальной нормы, содержащейся в Ст. 205 УК РФ.

По мнению В. С. Егорова, рассматриваемое примечание не относится к специальному случаю освобождения от уголовной ответственности, а является добровольным отказом от преступления [4, с. 105]. Аналогичной позиции придерживаются Л. Д. Гаухман, отмечающий, что в качестве условия освобождения в названном примечании предусмотрен добровольный отказ от данного преступления [3, с. 6], а также С. Н. Шатилович [12, с. 113] и В. В. Сверчков [9, с. 63].

Альтернативную позицию занимают А. В. Савкин [8, с. 105], Р. В. Соловьев [10, с. 29], Е. Д. Ермакова [5, с. 12]. По их мнению, примечание, содержащееся в рассматриваемой статье, относится к институту деятельного раскаяния.

Л. В. Иногамова-Хегай считает, что норма - примечание к ст. 205 УК РФ имеет двойственную природу: с одной стороны, является специальным видом освобождения от уголовной ответственности, с другой - добровольным отказом от преступления [6, c. 44]. Подобную позицию поддерживает А. Г. Антонов [2, с. 69].

Из приведенных выше мнений следует сделать вывод, что понимание применения примечания к анализируемой статье УК РФ неоднозначно, дискуссионно. В целях выработки единой позиции по данному вопросу рассмотрим проблему подробнее.

Как было указано выше, ч. 1 ст. 205 УК РФ характеризуется, во-первых, конкретными действиями (взрыв, поджог и т. д.) человека, направленными на совершение акта терроризма. Примечание в данном случае выступает как норма, предотвращающая определенные действия. При этом необходимо различать момент окончания преступления, то есть если преступник выполнил действия по недопущению террористического акта на стадии приготовлений и сообщил об этом органам власти, то данная ситуация будет квалифицирована по ст. 31 УК РФ (добровольный отказ от преступления), так как виновный отказался от исполнения своих действий, направленных на совершение общественно опасного деяния, тем самым освободив себя от уголовной ответственности и предотвратив опасность готовящегося преступления. В. В. Мальцев считает, что после совершения действий, создающих опасность наступления закрепленных в данных статье последствий, добровольно отказаться от уже выполненного террористического акта нельзя. Исходя из этого следует вывод, что добровольно отказаться от уже выполненного преступления невозможно, тогда как предотвратить наступление последствий еще возможно [7, c. 475]. Нельзя не согласиться с данной позицией, так как если лицо, осуществляющее подготовку, до наступления последствий террористического акта имеет возможность предотвратить его и предупредить органы власти и выполняет данные требования, то данное действие не будет относиться к добровольному отказу от преступления, а будет квалифицироваться как выполнение специального условия, которое содержится в примечании к ст. 205 УК РФ. Смоделируем ситуацию, при которой рассмотренное яв- 
ление будет трактоваться весьма неоднозначно. Так, закладка бомбы с детонатором или часовым механизмом, находящейся в задуманном для теракта месте, будет относиться к оконченной стадии приготовления, и добровольный отказ в таком случае невозможен. Вместе с тем если лицо, выполняющее действия по подготовке общественно опасного деяния, сообщило в органы власти о том, что в определенном месте и в конкретное время будет совершен инцидент, и способствовало предотвращению данного деяния, то оно будет освобождено от уголовной ответственности, если в действиях этого лица не содержится иного состава преступления.

Таким образом, в случае осуществления конкретных действий, описанных в ст. 205 УК РФ, может применяться как норма добровольного отказа от преступления, так и примечание к ст. 205 УК РФ. По своему смыслу обе нормы направлены на освобождение лица от уголовной ответственности вследствие выполнения определенных действий, которые имеют схожую природу.

Во-вторых, в ч. 1 ст. 205 УК РФ речь идет об угрозе совершения конкретных действий, закрепленных в данной статье. Как и в первом случае, реализация примечания к Ст. 205 УК РФ направлена на предотвращение объявления угрозы лицу, группе лиц, обществу в целом. Однако здесь также необходимо различать стадию оконченного преступления. Если преступником была высказана угроза, то ни добровольный отказ от преступления, ни примечание действовать не будут. Но если данная угроза была прервана, не закончена, тогда будет применено примечание, содержащееся в рассматриваемой статье.

В обоих деяниях одним из главных критериев является своевременность. Деяния характеризуются выполнением определенных действий как на стадии приготовления в случае отказа от преступления, так и на стадии предотвращения и сообщения органам власти. Своевременность в данном случае является определенным промежутком времени, в течение которого органы власти имеют возможность предотвратить террористический акт. Однако в случае если данное предупреждение было осуществлено заведомо поздно, то ни о каком освобождении от уголовной ответственности речи быть не может: оно возможно только при своевременном сообщении.

Помимо своевременности не менее важным критерием является и способствование предотвращению террористического акта, то есть осуществление определенных действий, направленных на содействие органам власти в предотвращении общественно опасного деяния. В случае если акт терроризма был осуществлен, но виновный способствовал процессу предотвращения, то он освобождается от уголовной ответственности.

Исходя из смысла примечания к рассматриваемой статье, законодатель руководствовался позицией не только по предотвращению террористического акта, подготовка к которому по своей сути осуществляется на данный момент, но и предупреждению данного состава преступления еще на начальных стадиях подготовки. Данное мнение является обоснованным, так как сам по себе акт терроризма является деянием, нарушающим общественную безопасность, которая защищена уголовно-правовыми нормами, то есть законодатель готов идти на уступку в отношении виновного ради защиты общественных отношений и интересов.

Хотелось бы обратить внимание на позицию А. Г. Антонова, который предложил усилить примечание к рассматриваемой статье и изложить ее в новой редакции: «если оно своевременным предупреждением органов власти создало реальную возможность предотвращения акта терроризма или иным способом предотвратило его осуществление», тем самым отразив реальную возможность защиты конкретных общественных отношений [2, с. 69]. Данное предложение, по нашему мнению, целесообразно, потому что в настоящее время в тексте примечания к рассматриваемой статье речь идет лишь о возможности защиты общественных отношений, которым может быть нанесен ущерб, но никак не о реальной, фактической защите. С учетом того, что террористический акт является общественно опасным деянием, которое наносит вред как общественной безопасности, общественному порядку, так и жизни и здоровью людей, различным объектам, строениям, зданиям и, как следствие, государству в целом, законодателю необходимо акцентировать внимание на защите, а не на возможности такой защиты.

Помимо этого, необходимо выделить в примечании оценочный критерий участия виновного в предотвращении инцидента, что позволит более детально и ясно оценивать постпреступное поведение виновного, нацеленное на предотвращение последствий террористического акта. Данный критерий будет направлен на активизацию 
виновного в плане взаимодействия с органами власти в целях предотвращения акта терроризма. В случае если лицо сообщило информацию о готовящемся или готовом к исполнению террористическом акте неразборчиво, нечетко или с целью замедлить процесс предотвращения рассматриваемого общественно опасного деяния, то это будет являться основанием неприменения специальной нормы освобождения от уголовной ответственности в связи с отсутствием активности в способствовании предотвращению акта терроризма. В связи с вышеизложенным предлагаем новую редакцию примечания к ст. 205 УК РФ: «если оно своевременным предупреждением органов власти создало реальную возможность предотвращения акта терроризма или иным способом активно способствовало предотвращению террористического акта».

Также необходимо уточнить, что законодатель подразумевает под фразой «или иным способом способствовало предотвращению террористического акта». На сегодняшний день в научной литературе отсутствуют мнения по данному вопросу. Однако стоит отметить, что иные действия, которые будут способствовать предотвращению акта терроризма, должны быть перечислены или классифицированы и обоснованы, так как на данный момент в законе отсутствует такой перечень, что дает широкие полномочия правоприменителям при выполнении служебных задач и виновным при выполнении условия, содержащегося в норме-примечании.

Исходя из содержания примечания, законодатель либо готов освободить лицо от уголовной ответственности в случае, когда виновным были совершены абсолютно любые действия для предотвращения террористического акта, либо не продумал до конца данную норму, потому что многие действия могут способствовать предотвращению террористического акта, однако при этом будут наносить вред другим общественным отношениям. К таковым можно отнести ситуацию, в которой лицо предупредит органы власти и предотвратит террористический акт, в случае если в отношении виновного будут совершены какие-либо действия личного или публичного характера органами власти или людьми, к примеру лицо заложило бомбу и сообщает в какие-либо органы власти об этом, в момент разговора заявляет, что обезвредит бомбу, если они выполнят его условие. Данное действие предотвратит террористический акт, но тогда виновный должен получить то, изза чего он способствовал предотвращению террористического акта: деньги, имущество и пр. Смоделируем ситуацию, в которой группа лиц заранее договорилась совершить поджог жилого здания в определенное время, все необходимые орудия и средства были заготовлены рядом с местом запланированного преступления. За несколько часов до реализации задуманного один из участников передумал осуществлять общественно опасное деяние и решил сообщить об этом в органы власти, тем самым он готов оказать содействие в предотвращении поджога, показать место, где хранятся средства совершения преступления, и передать информацию о других участниках преступления. Однако он боится за свою безопасность и передаст информацию только в том случае, если ему будет обеспечена защита. В данной ситуации виновный готов способствовать предотвращению террористического акта, но только в случае выполнения его условия о предоставлении защиты. Еще одна ситуация: один из участников группы, кем был подготовлен террористический акт, по личным соображениям сообщил в органы власти информацию об этом и показал, где находятся взрывчатые вещества, тем самым предотвратив его. В данном случае виновный оказал содействие органам власти в предупреждении последствий акта терроризма без каких-либо условий. Исходя из содержания ст. 205 УК РФ, целью террористов является дестабилизация деятельности органов власти или международных организаций либо воздействие на принятие ими решений, а также угроза совершения указанных действий в целях воздействия на принятие решений органами власти или международными организациями. То есть если лицо, намеревающееся поспособствовать предупреждению террористического акта, выдвигает требование личного характера в целях защиты себя и своих родственников, а также в силу особой опасности террористического акта, необходимо применять примечание к рассматриваемой статье. Поэтому считаем целесообразным классифицировать требования при способствовании предупреждению террористического акта, которые могут возникнуть в момент сообщения о готовящемся акте терроризма, следующим образом:

- условия имущественного характера;

- условия неимущественного характера;

- отсутствие условий. 
Помимо рассмотренных проблем, стоит отметить одно из условий применения примечания к ст. 205 УК РФ, которое состоит в отсутствии в действиях виновного иного состава преступления. Большая часть террористических актов происходит с применением оружия, взрывчатых веществ, взрывных устройств, сопровождается совершением каких-либо других общественно опасных деяний, имеющих признаки состава преступления. Например, лицо сообщило в уполномоченный орган власти о готовящемся акте терроризма и способствовало его предотвращению, однако у него обнаружили наркотические вещества, что подпадает под действие ст. 228 УК РФ. Исходя из условия, содержащегося в специальной норме ст. 205 УК РФ, лицо не будет освобождено от уголовной ответственности, так как в его действиях имеется иной состав преступления.

Таким образом, целесообразно устранить данное условие, так как в случае предотвращения террористического акта к лицу не смогут применить специальную норму ст. 205 УК РФ в связи с наличием иного состава преступления.

В заключение отметим, что террористический акт является преступлением, обладающим повышенной степенью общественной опасности, которое необходимо предупреждать на начальной стадии, чему активно способствует специальная норма к рассматриваемой статье Особенной части УК РФ. Исходя из этого, считаем, что предлагаемые изменения положительно отразятся на предотвращении виновными рассматриваемого преступления.

\section{СПИСОК ЛИТЕРАТУРЫ}

1. Антонов, А. Г. Специальные основания освобождения от уголовной ответственности : автореферат диссертации на соискание ученой степени доктора юридических наук / А. Г. Антонов. - Рязань, 2013. - 44 с.

2. Антонов, А. Г. Террористический акт: вопросы освобождения от уголовной ответственности / А. Г. Антонов // Юридическая наука и правоохранительная практика. - 2010. - № 3 (13). - С. 65-70.

3. Гаухман, Л. Уголовно-правовая борьба с терроризмом / Л. Гаухман // Законность. - 2001. - № 5. - С. 6-7.

4. Егоров, В. С. Освобождение от уголовной ответственности : монография / В. С. Егоров. - Москва : МПСИ, 2002. - 191 c. - ISBN 5-8397-0484-9.

5. Ермакова, Е. Д. Специальные случаи освобождения от уголовной ответственности в уголовном праве России : автореферат диссертации на соискание ученой степени кандидата юридических наук / Е. Д. Ермакова. - Рязань, 2006. -26 c.

6. Иногамова-Хегай, Л. В. Конкуренция норм уголовного права : автореферат диссертации на соискание ученой степени доктора юридических наук / Л. В. Иногамова-Хегай. - Москва, 1999. - 44 с.

7. Мальцев, В. В. Принципы уголовного права и их реализация в правоприменительной деятельности / В. В. Мальцев. - Санкт-Петербург, 2004. - 694 с. - ISBN 5-94201-323-3.

8. Савкин, А. В. Теоретические и правовые проблемы деятельного раскаяния в преступлении : монография / А. В. Савкин. - Москва, 2002. - 187 с. - ISBN 5-92305-213-2.

9. Сверчков, В. В. Деятельное раскаяние в нормах Общей и Особенной частей УК РФ / В. В. Сверчков // Российская юстиция. - 2001. - № 2. - С. 62-63.

10. Соловьев, Р. Специальные виды освобождения от уголовной ответственности / Р. Соловьев // Законность. 2001. - № 11. - С. 29-31.

11. Чаплин, Н. Ю. О соотношении понятий «устойчивость», «стабильность», «безопасность» в контексте исследования устойчивости государства / Н. Ю. Чаплин // Вестник Московского юридического института. - 2017. - № 1 (60). - C. $108-116$

12. Шатилович, С. Н. Освобождение от уголовной ответственности при особых формах преступной деятельности (соучастие в преступлении, неоконченное преступление, множественность преступлений) : учебно-практическое пособие. - 2-е изд., перераб. и доп. - Тюмень : Тюменский институт повышения квалификации сотрудников МВД России, 2014. - 143 с. - ISBN 978-5-93160-219-6.

\section{REFERENCES}

1. Antonov A. G. Special'nye osnovaniya osvobozhdeniya ot ugolovnoj otvetstvennosti. Avtoref. diss. dokt. yurid. nauk [Special grounds for exemption from criminal liability. Author's abstract of the diss. Dsc. in Law]. Ryazan, 2013. 44 p. (In Russ.).

2. Antonov A. G. Terroristicheskij akt: voprosy osvobozhdeniya ot ugolovnoj otvetstvennosti [Act of terrorism: exemption from criminal liability]. YUridicheskaya nauka i pravoohranitel'naya praktika - Jurisprudence and law enforcement practice, 2010, no. 3 (13), pp. 65-70. (In Russ.).

3. Gauhman L. Ugolovno-pravovaya bor'ba s terrorizmom [The Criminal law fight against terrorism]. Zakonnost' - Legality, 2001, no. 5, pp. 6-7. (In Russ.).

4. Egorov V. S. Osvobozhdenie ot ugolovnoj otvetstvennosti [Exemption from criminal liability]. Moscow, 2002. 191 p. (In Russ.).

5. Ermakova, E. D. Special'nye sluchai osvobozhdeniya ot ugolovnoj otvetstvennosti v ugolovnom prave Rossii. Avtoref. diss. kand. yurid. nauk [Special cases of exemption from criminal liability in the criminal law of Russia. Author's abstract of the diss. PhD. in Law]. Ryazan, 2006. 26 p. (In Russ.).

6. Inogamova-Hegaj L. V. Konkurenciya norm ugolovnogo prava. Avtoref. diss. dokt. yurid. nauk [Competition in criminal law. Author's abstract of the diss. Dsc. in Law]. Moscow, 1999. 44 p. (In Russ.).

7. Mal'cev V. V. Principy ugolovnogo prava $i$ ih realizaciya v pravoprimenitel'noj deyatel'nosti [The principles of criminal law and their implementation in law enforcement]. St. Petersburg, 2004. 694 p. (In Russ.).

8. Savkin A. V. Teoreticheskie i pravovye problemy deyatel'nogo raskayaniya v prestuplenii [Theoretical and legal problems of active remorse in crime]. Moscow, 2002. 187 p. (In Russ.). 
9. Sverchkov V. V. Deyatel'noe raskayanie v normah Obshchej i Osobennoj chastej UK [Active repentance in the norms of the General and Special parts of the Criminal Code]. Rossijskaya yusticiya - Russian justice, 2001, no. 2, pp. 62-63. (In Russ.). 10. Solov'ev R. Special'nye vidy osvobozhdeniya ot ugolovnoj otvetstvennosti [Special types of exemption from criminal liability]. Zakonnost' - Legality, 2001, no. 11, pp. 29-31. (In Russ.).

11. CHaplin N. YU. O sootnoshenii ponyatij «ustojchivost'», "stabil'nost'», «bezopasnost'» v kontekste issledovaniya ustojchivosti gosudarstva [On the correlation of the concepts of "stability", "stability", "security" in the context of the study of state stability]. Vestnik Moskovskogo yuridicheskogo instituta - Bulletin of the Moscow Law Institute, 2017, no. 1 (60), pp. 108-116. (In Russ.).

12. SHatilovich S. N. Osvobozhdenie ot ugolovnoj otvetstvennosti pri osobyh formah prestupnoj deyatel'nosti (souchastie $v$ prestuplenii, neokonchennoe prestuplenie, mnozhestvennost' prestuplenii) [Exemption from criminal liability for special forms of criminal activity (complicity in a crime, unfinished crime, multiplicity of crimes)]. Tyumen, 2014. 143 p. (In Russ.). 